\title{
The Impact of Spirometry on Diagnosis and Treatment: Asthma in Children
}

\author{
Md. Kamruzzaman, ", Habiba Jesmin ${ }^{2}$, Probir Kumar Sarkar ${ }^{1}$, Nabila Akhand ${ }^{1}$, \\ Mosharraf Hossain ${ }^{1}$, Sarbon Tohura ${ }^{1}$ \\ ${ }^{1}$ Department of Paediatric Respiratory Medicine, Dhaka Shishu (Children) Hospital, Dhaka, Bangladesh \\ ${ }^{2}$ Department of Paediatrics, Shaikh Hasina Medical College Hospital, Tangail, Bangladesh
}

Email address:

dr.kamru107@gmail.com (Md. Kamruzzaman)

${ }^{*}$ Corresponding author

\section{To cite this article:}

Md. Kamruzzaman, Habiba Jesmin, Probir Kumar Sarkar, Nabila Akhand, Mosharraf Hossain, Sarbon Tohura. The Impact of Spirometry on Diagnosis and Treatment: Asthma in Children. American Journal of Pediatrics. Vol. 7, No. 1, 2021, pp. 1-4.

doi: $10.11648 /$ j.ajp.20210701.11

Received: November 5, 2020; Accepted: January 13, 2021; Published: January 30, 2021

\begin{abstract}
Introduction: Spirometry is a common method that is used to determine common lung raspatory diseases and lung capacity. It is also used to treat asthma, an extremely common lung disease. Aim of the study: The aim of this study is to assess the clinical improvement and changes in spirometric measurements with treatment in children with newly diagnosed asthma. Methods: This was a cross-sectional prospective study was conducted in the Department of Paediatrics, of Dhaka Shishu (Children) Hospital, Dhaka, Bangladesh during the period from January 2019 to December 2019. This prospective study included 50 children between 5-15 years. of age who were newly diagnosed as cases of asthma based on symptoms and medical history. Baseline symptom score and spirometric measurements were determined at the first visit. The children were treated and followed up of 3 to 6 months of initiating treatment. Symptom scores and spirometric measurements were repeated at every visit. Result: The majority of the patients were from the age group of 7-9 years, and gender-wise $2 / 3^{\text {rd }}$ of the patients were male. The mean symptom score showed the greatest improvements after the 3-month follow up, and continued to show slow but steady improvements at the 6-month follow-up. Conclusion: Spirometry makes a great impact on recognizing and treating respiratory complications, and needs to be used more widely to recognize and remove its limitations.
\end{abstract}

Keywords: Spirometry, Asthma, Diagnosis, Treatment

\section{Introduction}

Spirometry is known as the commonest lung function test done to date.[1] It measures what quantity of air is moved in and out of the lungs and the way and how fast the air moves. To induce the most effective results, your child will be asked to follow very specific instructions. Most youngsters can do spirometry by age 6 , though some preschoolers are able to perform the test at a younger age. [2] Asthma could be a chronic disease of airways characterized by bronchial hyperresponsiveness and reversible airway obstruction.[3] However, most asthmatic children, independent of the disease severity, are found to possess normal forced expiratory volume (FEV) values especially when asymptomatic. [4-6] Hence, the essential role of pulmonary function tests in both short- and long-term evaluations of childhood asthma remains controversial so far.[7] Another thing to notice is that consistent spirometric measurements depend heavily on the patient's ability or inability to perform a forceful expiratory maneuver which is strenuous in young children. Hence, the clinical picture in terms of signs and symptoms is additionally of paramount significance. [8] The lung function measurements give information about the patients' physiology objectively, whereas symptoms give more information about how the disease affects the patient. it's known that with treatment there's improvement in both symptoms and lung function measures, the degree of improvement in each of the parameters aren't yet clear. The aim of this study is to see the clinical improvement and therefore the changes within the spirometric measurements with treatment in newly diagnosed cases of asthma in 
children and to match the change within the symptom. This goal of this study was to gauge the quantifiable progress and changes in spirometric measurements with treatment in children who have newly been diagnosed with asthma and to check the deviations within the symptom score and spirometric measurements. [9]

\section{Methodology and Materials}

This was a cross-sectional prospective study and was conducted in the Department of Pediatrics, Dhaka Shishu Hospital, Dhaka, Bangladesh during the period from January 2019 to December 2019. This prospective study included 50 children between 5-15 years of age who were newly diagnosed with cases of asthma based on symptoms and medical history. Baseline symptom score and spirometric measurements were determined at the first visit. The children were treated and followed up after 3 and 6 months of initiating treatment. Symptom scores and spirometric measurements were repeated at every visit. The monthly patient profile was compiled, and data were presented in tables with the use of Microsoft Excel and SPSS.

\section{Result}

The age of the patients 5-7 years. $33(66.67 \%)$ were males and $17(33.33 \%)$ were females. The male: female ratio was almost 2:1 (Figure 1). At the time of the follow-up, the highest respondents found were in 7-9 years, at $36 \%(n=18)$, Between the age group of $9-12$ years, we found $26 \%,(n=13)$, in $5-7$ age group, we found $22 \%(n=11)$ and the remaining $16 \%(n=8)$ were found within the age group of $12-15$, Mean \pm SD found $(11 \pm 3.56)$ (Table 1$) .84 \%(n=42)$ of the patients belonged to the mild persistent type and $16 \%(n=8)$ were of the moderate persistent type of asthma. $\mathrm{P}<0.05$ is considered significant compared to baseline. Values are mean $\pm \mathrm{SD}(\mathrm{n}=50)$; where FEV1-Forced Expiratory Volume in 1 second; FVC- Forced
Vital Capacity; PEFR-Peak Expiratory Flow Rate. The mean symptom score, mean FEV1 was found to be $(1.61 \pm 0.8)$ for 3 months and $(1.79 \pm 0.83)$ for 6 months, FVC $(1.74 \pm 0.83)$ for 3 months and (1.74 \pm 0.83$)$ for 6 months, FEV1/FVC (90.67 \pm 8.96$)$ for 3 months and $(91.8 \pm 6.49)$ for 6 months and last mean of PEFR (2.79 \pm 0.76$)$ for 3 months $(3.32 \pm 0.92)$ values at each visit and the improvement in the various parameters when compared to baseline (Table 2). Significant improvement in the symptom score and lung function parameters, FEV1, and FVC was seen at three months. PEFR was found to show improvement at six months. FEV1/ FVC did not show significant improvement during the study period. Table 3 shows improvement in the various parameters during followup when compared to the previous visit. Improvement was noticed in all the spirometric parameters at six months follow up.

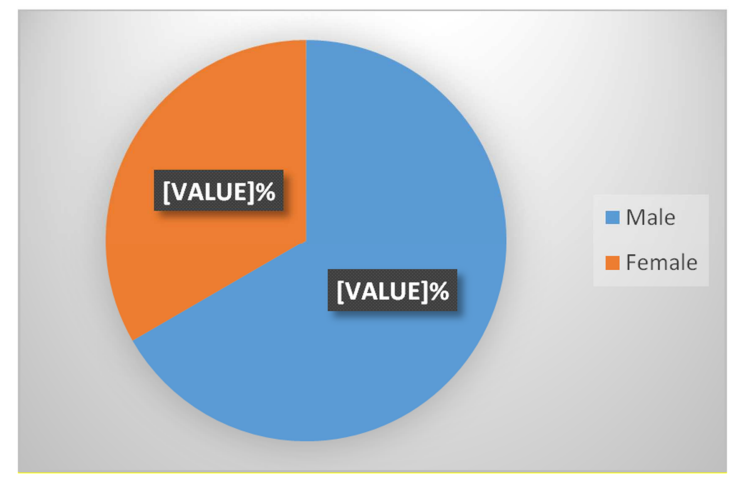

Figure 1. Distribute the study people according to gender where $(n=50)$.

Table 1. Distribute the study people according to age $N=50$.

\begin{tabular}{llll}
\hline Age Distribution & n & \% & Mean \pm SD \\
\hline $5-7$ & 11 & $22 \%$ & \\
$7-9$ & 18 & $36 \%$ & $11 \pm 3.56$ \\
$9-12$ & 13 & $26 \%$ & \\
$12-15$ & 8 & $16 \%$ & \\
\hline
\end{tabular}

Table 2. Mean symptom score, and lung function parameters at baseline 3 months and 6 months where $N=50$.

\begin{tabular}{lllll}
\hline & Mean total symptom score & Mean FEV1 (1) & Mean FVC (1) & Mean FEV1/FVC \\
\hline Baseline & $19.28 \pm 4.18$ & $1.46 \pm 0.84$ & $1.55 \pm 0.9$ & $93.83 \pm 9.06$ \\
3 months & $24.31 \pm 2.46$ & $1.61 \pm 0.8$ & $1.74 \pm 0.83$ & $90.67 \pm 8.96$ \\
6 months & $26.09 \pm 2.14$ & $1.79 \pm 0.83$ & $1.74 \pm 0.83$ & $91.8 \pm 6.49$ \\
\hline
\end{tabular}

Table 3. Improvement in symptom score and lung function parameters $N=50$.

\begin{tabular}{lll}
\hline Improvement in parameter compared to the previous visit & At 3 months & At 6 months \\
\hline Symptom score & $\mathrm{P}=0.02$ & $\mathrm{~N}=0.04$ \\
FEV1 & $\mathrm{NS}$ & $\mathrm{P}=0.02$ \\
FVC & $\mathrm{P}=0.03$ & $\mathrm{P}=0.03$ \\
PEFR & $\mathrm{NS}$ & $\mathrm{P}=0.04$ \\
\hline
\end{tabular}

\section{Discussion}

Spirometry can be considered as a widely used method for determining the lung capacity and lung functions of a person. It is a uniquely valuable tool, often used to determine whether or not a patient has asthma, chronic obstructive pulmonary disease (COPD), and other conditions that affect breathing, by measuring how much air one can inhale and exhale, and how quickly you can exhale. [9] But this can be an irritating process for younger patients who need to stay still for a prolonged time to get a proper reading. [1] Asthma and (COPD) are common diseases all around the world, which can cause patients and society considerable difficulties. 
These are harmful diseases that can cause substantial difficulty in life and can also cause morbidity and death, as these are diseases that can affect both the young and the elderly. [10] This study was performed to understand the impact of spirometry in both diagnosis and treatment, focusing mainly on children with asthma.

The collected data shows that at the time of the study, the ratio of male to female patients undergoing spirometry is almost at $2: 1$. The average age of the patients can be seen as 11 , although a large portion of the patients belonged to the age group of 7-9 years, with the number of patients above the age of 12 being the lowest in the sample size.

$84 \%$ of the patients were under the category of mild persistent and the rest 8 patients fell under the moderate persistent category. These categories were determined using the guidelines set by NAEPP. [11]

The follow up was done 3 months and 6 months after the initial assessment, with inputs from both the patients themselves and their parents. This brought to attention an interesting fact that the parental reports and the patients differed depending on the age of the patients. This can be explained by examining another study, where the original report was more likely to correlate with the parents' reports with the patient under the average age of 11 , while parental and child's reports correlated more strongly with the original reports. [12] This implies that in cases of patient-based information, it is more reliable to focus on parental reports with patients between the age of 6-11 years of age. And in the age group of 12 to 18 years, both parental and patients' reports can be comparable with original reports. [12]

From the follow-up reports, we can see some initial positive outcomes starting from the $3^{\text {rd }}$ month follow up, with the mean FEV1/FVC falling by 3 scores. This brings up the mean total symptoms score from $19.28 \pm 4.18$ to $24.31 \pm 2.46$. Further improvements can be seen at the time of the 6 months follow up. Mean FVC did not change any further after the initial follow up at 3 months. The 6 months follow shows the mean FEV1/FVC increasing by more than 1 point compared to the 3-month check-up, while still being below the initial baseline score. The change in other aspects at the 6-month follow-up is comparatively lower than the $3^{\text {rd }}$ month follow up. The mean total symptoms score was at $26.09 \pm 2.14$ after the $6^{\text {th }}$-month check-up.

When put into parameters, the results are more apparent from Table 3, where we can see that after 3 months checkup and 6 months checkup, the value of $P$ has gone up at a rate of 0.02 at symptom score. Quality of life had also improved at each follow-up visit and at the termination of the study, determined by the value of $\mathrm{P}<0.05$. The magnitude of improvement in QOL (Quality of Life) was similar to improvement in objective measures of pulmonary function; although these changes were not similar to changes in asthma symptom score. [13]

The whole study can conclude that spirometry is a valid method for treating patients with asthma, and can provide visible results.

\section{Limitations of the study}

Our study wasn't blinded so patient bias was present along with observer bias in subjective recording and this was a single-center study with small sample size. The lack of prior knowledge regarding the study subject found in the guardians also played a role in manipulating the results. So, for the prior mentioned reasons, the study results might not be reflected in the whole community.

\section{Conclusion and Recommendations}

The study proved that spirometry is a valid and preferred method for treating patients with asthma, and is also a primary resort for most medical institutes to determine any lung related illness. It is recommended to increase knowledge regarding spirometry in both the general populace and the medical professionals to widespread the use of spirometry. Primary knowledge regrading spirometry and its proper uses should be taught to both doctors and nurses, and the number of spirometry machine should be increased. Patients need to be more aware of the complications and advantages of spirometry to make more knowledgeable decisions.

\section{References}

[1] Anandi, S., Tullu, M. S., \& Lahiri, K. (2016). Evaluation of symptoms \& spirometry in children treated for asthma. The Indian journal of medical research, 144(1), 124.

[2] Pulmonary Function Testing in Children," Patient education | information series, Am J Respir Crit Care Med Vol. 189, P5P6, 2014.

[3] Bateman ED, Hurd SS, Barnes PJ, Bosquet J, Drazen JM, FitzGerald M, et al. Global strategy for asthma management and prevention: GINA executive summary. Eur Respir J 2008; 31: 143-78.

[4] Spahn JD, Cherniack R, Paull K, Gelfand EW. Is forced expiratory volume in one second the best measure of severity in childhood asthma? Am J Respir Crit Care Med 2004; 169: 784-6.

[5] The Childhood Asthma Management Program Research Group. Long-term effects of budesonide or nedocromil in children with asthma. N Engl J Med 2000; 34: 1054-63.

[6] Bacharier LB, Strunk RC, Mauger D, White D, Lemanske RF Jr, Sorkness CA. Classifying asthma severity in children: mismatch between symptoms, medication use, and lung function. Am J Respir Crit Care Med 2004; 170: 426-32.

[7] Expert Panel Report 3 National Heart, Lung and Blood Institute Guidelines for the diagnosis and management of asthma. Available from: http://www.nhlbi.gov., accessed on August 16, 2009.

[8] Global strategy for asthma management and prevention. Available from: http://www.ginasthma.org., accessed on August 16, 2009.

[9] Derom, E., Van Weel, C., Liistro, G., Buffels, J., Schermer, T., Lammers, E.,... \& Decramer, M. (2008). Primary care spirometry. European Respiratory Journal, 31(1), 197-203. 
[10] Colice, G. L. (2012). Pragmatic research and outcomes in asthma and COPD. Pragmatic and observational research, 3, 11.

[11] Stout, J. W., Visness, C. M., Enright, P., Lamm, C., Shapiro, G., Gan, V. N.,... \& Mitchell, H. E. (2006). Classification of asthma severity in children: the contribution of pulmonary function testing. Archives of pediatrics \& adolescent medicine, 160(8), 844-850.

[12] Zhang, L., Avila, L., Leyraud, L., Grassi, S., Raquel, T., Bonfanti, T., \& Ferruzzi, E. (2005). Accuracy of parental and child's report of changes in symptoms of childhood asthma. Indian pediatrics, 42(12), 1220-1225.

[13] Singh, M., Mathew, J. L., Malhi, P., Srinivas, B. R., \& Kumar, L. (2004). Comparison of improvement in quality of life score with objective parameters of pulmonary function in Indian asthmatic children receiving inhaled corticosteroid therapy. Indian pediatrics, 41(11), 1143-1147. 